\title{
BMJ Open Managing new-onset atrial fibrillation in critically ill patients: a systematic narrative review
}

\author{
Liam Joseph O'Bryan (D) , ${ }^{1,2}$ Oliver C Redfern, ${ }^{1}$ Jonathan Bedford (i) , ${ }^{1}$ \\ Tatjana Petrinic, ${ }^{3}$ J Duncan Young, ${ }^{1}$ Peter J Watkinson (iD ${ }^{1}$
}

To cite: O'Bryan LJ, Redfern OC, Bedford J, et al. Managing new-onset atrial fibrillation in critically ill patients: a systematic narrative review. BMJ Open 2020;10:e034774. doi:10.1136/ bmjopen-2019-034774

- Prepublication history and additional material for this paper are available online. To view these files, please visit the journal online (http://dx.doi. org/10.1136/bmjopen-2019034774).

Received 08 0ctober 2019 Revised 17 January 2020 Accepted 03 March 2020

Check for updates

(C) Author(s) (or their employer(s)) 2020. Re-use permitted under CC BY-NC. No commercial re-use. See rights and permissions. Published by BMJ.

${ }^{1}$ Nuffield Department of Clinical Neurosciences, University of

Oxford, Oxford, UK

${ }^{2}$ St Vincent's Hospital Melbourne, University of Melbourne, Melbourne, Victoria, Australia

${ }^{3}$ Cairns Library, University of Oxford Health Care Libraries, Oxford, UK

Correspondence to Dr Liam Joseph O'Bryan; lobrya.2@gmail.com

\section{ABSTRACT}

Objectives The aim of this review is to summarise the latest evidence on efficacy and safety of treatments for new-onset atrial fibrillation (NOAF) in critical illness.

Participants Critically ill adult patients who developed NOAF during admission.

Primary and secondary outcomes Primary outcomes were efficacy in achieving rate or rhythm control, as defined in each study. Secondary outcomes included mortality, stroke, bleeding and adverse events.

Methods We searched MEDLINE, EMBASE and Web of Knowledge on 11 March 2019 to identify randomised controlled trials (RCTs) and observational studies reporting treatment efficacy for NOAF in critically ill patients. Data were extracted, and quality assessment was performed using the Cochrane Risk of Bias Tool, and an adapted Newcastle-Ottawa Scale.

Results $0 f 1406$ studies identified, 16 remained after full-text screening including two RCTs. Study quality was generally low due to a lack of randomisation, absence of blinding and small cohorts. Amiodarone was the most commonly studied agent (10 studies), followed by betablockers (8), calcium channel blockers (6) and magnesium (3). Rates of successful rhythm control using amiodarone varied from $30.0 \%$ to $95.2 \%$, beta-blockers from $31.8 \%$ to $92.3 \%$, calcium channel blockers from $30.0 \%$ to $87.1 \%$ and magnesium from $55.2 \%$ to $77.8 \%$. Adverse effects of treatment were rarely reported (five studies).

Conclusion The reported efficacy of beta-blockers, calcium channel blockers, magnesium and amiodarone for achieving rhythm control was highly varied. As there is currently significant variation in how NOAF is managed in critically ill patients, we recommend future research focuses on comparing the efficacy and safety of amiodarone, beta-blockers and magnesium. Further research is needed to inform the decision surrounding anticoagulant use in this patient group.

\section{BACKGROUND}

New-onset atrial fibrillation (NOAF) occurs in approximately $14 \%$ of critically unwell patients ${ }^{1}$; the incidence increases with greater severity of illness and in sepsis. ${ }^{2-4}$ NOAF can lead to haemodynamic instability ${ }^{5}$ and thromboembolic events. ${ }^{6}$ Critically ill patients with NOAF experience longer intensive care unit (ICU) stay, greater duration of mechanical

\section{Strengths and limitations of this study}

- Our systematic review is a broad assessment of the evidence surrounding the management of newonset atrial fibrillation (NOAF) in the critically ill patient.

- Our review is a significant update to previous reviews, as our search identified more studies specific to the management of NOAF.

- We included studies of non-cardiac critically unwell patients to ensure that our findings are generalisable to the intensive care unit patient.

- Due to limited randomised trial data and study heterogeneity, we did not conduct a meta-analysis and present a narrative synthesis of evidence.

ventilation and an increased risk of in-hospital mortality. ${ }^{48}$

Extensive guidelines exist for managing atrial fibrillation $(\mathrm{AF})$ in the community and the acute setting. ${ }^{9-11}$ However, the safety and efficacy of treatments in critically ill patients are less clear. ${ }^{12}$ For example, anticoagulation may fail to prevent stroke in critically ill patients with NOAF. ${ }^{13}$ In addition, directcurrent cardioversion (DCC) and pharmacological cardioversion are often unsuccessful during critical illness. ${ }^{14} 15$ Failure to attain rate or rhythm control in patients with $\mathrm{NOAF}$ has been linked with increased in-hospital mortality. ${ }^{3} 16$

Two previous systematic reviews have focused on the management of NOAF in the critically ill. ${ }^{2}{ }^{12}$ In 2008, Kanji et al reviewed evidence from randomised controlled trials (RCTs) reporting efficacy of pharmacological treatments. ${ }^{12}$ In 2015, Yoshida et al reviewed both RCTs and observational studies of epidemiology, prevention and management. ${ }^{2} \mathrm{~A}$ recent scoping review summarised the epidemiology, prevention and methods of management of NOAF in critically unwell patients. ${ }^{1}$ It included patients with pre-existing $\mathrm{AF}$ as well as patients outside ICU or in cardiac intensive 
care. As a scoping review, it did not report the effect on cardiac rhythm of the interventions identified. None of these reviews were able to make specific management or research recommendations due to the absence of highquality studies and significant population heterogeneity between studies.

\section{Objective}

The aim of this review is to summarise evidence from observational studies and randomised trials reporting outcomes of individual treatments for NOAF in critically ill adult patients. This review serves as an update, as the most recent review specific to only the management of NOAF was in 2008. We aim to identify more relevant studies than previous reviews by including studies of all treatments (including DCC and anticoagulation), observational studies and studies of new-onset supraventricular arrhythmias (SVAs), where $\mathrm{AF}$ is the predominant rhythm, in the critically ill.

\section{METHODS}

We report our review according to the Preferred Reporting Items for Systematic Reviews and Meta Analyses guidelines (see online supplementary appendix 1). ${ }^{17}$ While the methods of our review were specified a priori, no protocol was published.

\section{Study eligibility}

We considered all RCTs and observational studies published in peer-reviewed journals. We included foreign language papers where an English translation was available. We excluded case reports, conference abstracts, letters to the editor, editorials and any other publication that did not report primary data.

We included studies of adult patients (age $\geq 16$ ) who developed NOAF during admission to a medical, surgical or general ICU. To improve the search yield, we included studies of sepsis outside the ICU and of new-onset SVAs where $\mathrm{AF}$ was the dominant $(>70 \%)$ arrhythmia. We defined NOAF as AF occurring during admission in a patient with no history of chronic AF. We excluded studies conducted in specialised (neurosurgical or cardiothoracic) ICUs and studies specific to medical or surgical cardiac patients.

We included all studies reporting data on the outcome of a single intervention. The primary outcome of interest was efficacy in achieving rhythm or rate control, as defined by each study. Secondary outcomes included mortality, stroke, bleeding and adverse events. No limitation was placed on the timing of outcome assessment.

\section{Search strategy}

We searched the Medical Literature Analysis and Retrieval System Online (MEDLINE-OVID interface, 1946 to present), Excerpta Medica (EMBASE-OVID interface, 1974 to present) and Web of Science (Clarivate Analytics interface, 1945 to present) databases on 11 March 2019, using medical subject headings and keywords (full list shown in online supplementary appendix 2). Search terms were designed to capture all SVAs, including 'AF', 'atrial flutter', 'supraventricular tachycardia' and 'atrial arrhythmia'. Terms including 'critical care', 'critically ill', 'intensive care' and 'sepsis' were used to define the setting. General terms such as 'treatment' were used alongside specific treatments including 'beta-blocker', 'calcium channel blocker', 'direct current', 'magnesium' and 'anticoagulation'. Snowballing was performed by assessing references in relevant review articles. The search strategy was formulated in consultation with a medical librarian (TP).

\section{Study selection}

We imported search results into Mendeley Desktop (V1.19.3, Mendeley), which was used to identify duplicate publications for removal. Two independent reviewers (LJO and JB) then screened titles and abstracts for eligibility. Studies were eligible for full-text analysis where the abstract appeared to fulfil our inclusion criteria or where there was uncertainty. We retrieved full-text articles and assessed them for relevance using Rayyan software (Rayyan, HBKU, Qatar) to allow blinding between the reviewers (LJO and JB). ${ }^{18}{ }^{19}$ We discussed disagreements and consulted a third reviewer (DY) if consensus could not be reached.

\section{Data extraction}

One author (LJO) performed data extraction; the author was not blinded to study authors or institutions. Data extracted from each study included: design, setting, population, interventions, outcomes, timing of assessment and results (see online supplementary appendix $3)$. Where studies reported data separately for new or chronic arrhythmias, we extracted only data related to NOAF. We simplified SVA to NOAF and grouped drugs by class (beta-blockers, calcium channel blockers or anticoagulants). We extracted outcomes only when the effect of a single intervention was evaluated in a cohort of greater than 10 participants. We extracted per cent success for each treatment (with respect to a given outcome) and relative risks or ORs were provided. We calculated per cent success if it was not reported.

\section{Risk of bias assessment}

We conducted a risk of bias assessment for all observational studies using an adapted Newcastle-Ottawa Scale (NOS) (see online supplementary appendix 4). ${ }^{20} 21$ This adaptation was designed for non-randomised trials reporting the incidence of NOAF in critical care. ${ }^{21}$ RCTs were assessed using the Cochrane Risk of Bias Tool for Randomised Controlled Trials (Supplemental Appendix 5). ${ }^{22}$

\section{Statistical analysis}

The primary outcome was efficacy in rhythm or rate control, expressed as a proportion. Outcome data for 


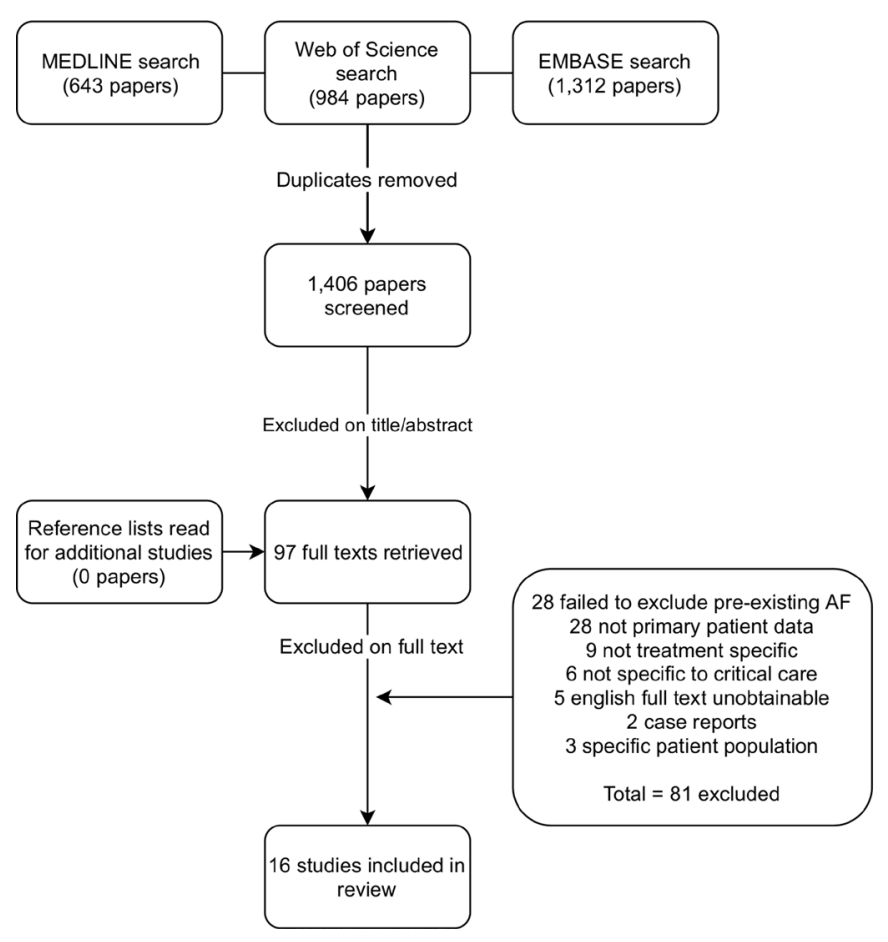

Figure 1 PRISMA flow chart of search results and screening. PRISMA, Preferred Reporting Items for Systematic Reviews and Meta Analyses.

RCTs were expressed by calculating an OR using provided data.

\section{Patient and public involvement}

No patients were involved in this study which used data only from published materials.

\section{RESULTS}

\section{Search results}

We identified 1406 unique studies from our search, of which 97 remained after abstract screening (figure 1). After full-text review, 16 eligible studies were identified (see online supplementary appendix 3). Of these, 13 were of patients treated in ICU and the remaining 3 were of patients with sepsis managed in hospital (ICU and nonICU), including only the sepsis arm of one study of nonICU patients. ${ }^{23}$

\section{Risk of bias}

We identified 2 RCTs, 3 prospective cohort and 11 retrospective cohort studies. Thirteen of these studies reported an outcome of treatment efficacy in achieving rate or rhythm control. Of two RCTs reporting this outcome, both had unclear risk of bias in allocation concealment and randomisation (see online supplementary appendix 5). ${ }^{24} 25$ One RCT also had unclear blinding of outcome assessment ${ }^{25}$ while the other had an unclear risk of selective reporting. ${ }^{24}$ Observational studies reporting rate and rhythm control for critically ill patients with NOAF varied in quality (see online supplementary appendix 6). The most common reasons for risk of bias in these studies are outlined in table 1 .

Studies reporting outcomes of stroke and bleeding associated with anticoagulation were of higher methodological quality, with less risk of bias. ${ }^{13} 23$ Risks of bias in each of these studies were due to retrospective study design and basis in a population of patients with sepsis rather than a generally critically unwell patient group. One study of mortality associated with rate and rhythm control agents used in septic patients with NOAF was of high methodological quality but with risks of bias due to retrospective design and a septic patient population. ${ }^{15}$

\section{Study characteristics}

Studies are described in supplemental appendix 3. Table 2 describes the interventions and outcomes for each of the 16 studies. Amiodarone was the most reported intervention followed by beta-blockers and calcium channel blockers. There were fewer studies of DCC, magnesium and anticoagulation. Studies of less common therapies (pilsicainide, digoxin and propafenone) were grouped. A meta-analysis of RCTs was not performed due to a lack of common interventions.

Rhythm control was the most frequently reported outcome. Although beta-blockers and calcium channel blockers are considered rate control agents, their efficacy was primarily reported in regard to rhythm control. Timing of outcome assessment varied between 2 hours ${ }^{24}$ and 7 days. ${ }^{16}$ Definitions of successful rhythm control varied with regards to how long sinus rhythm (SR) was maintained; the most common definition used was SR maintained for 24 hours. We did not pool study outcomes

\begin{tabular}{|c|c|c|}
\hline Domain of bias & Criteria & Main issues \\
\hline \multirow[t]{2}{*}{ Selection bias } & Representativeness of study population & $\begin{array}{l}\text { Population of sepsis less representative of generally critically } \\
\text { unwell }^{162631}\end{array}$ \\
\hline & Study size & Treatment group size $(n<100)^{61626-293132}$ \\
\hline Comparability & $\begin{array}{l}\text { Comparability of cohorts based on study } \\
\text { design or analysis }\end{array}$ & $\begin{array}{l}\text { Groups not adequately comparable by study design or } \\
\text { analysis }{ }^{143132}\end{array}$ \\
\hline \multirow[t]{3}{*}{ Outcomes } & Study design & Retrospective design 56162628 30-32 \\
\hline & Assessment of outcomes & Failure to describe ECG use for outcome assessment ${ }^{52631}$ \\
\hline & Adequacy of follow-up & No study reported significant loss to follow-up \\
\hline
\end{tabular}




\begin{tabular}{|c|c|c|c|c|}
\hline Therapy & Rhythm control & Rate control & Mortality & Total \\
\hline Amiodarone & $\begin{array}{l}9 \text { studies } \\
1 \mathrm{RCT}\end{array}$ & 0 studies & $\begin{array}{l}2 \text { studies } \\
1 \mathrm{RCT}\end{array}$ & $\begin{array}{l}10 \text { studies } \\
1 \mathrm{RCT}\end{array}$ \\
\hline Beta-blockers & $\begin{array}{l}7 \text { studies } \\
1 \mathrm{RCT}\end{array}$ & $\begin{array}{l}1 \text { study } \\
0 \text { RCTs }\end{array}$ & $\begin{array}{l}1 \text { study } \\
0 \text { RCTs }\end{array}$ & $\begin{array}{l}8 \text { studies } \\
1 \mathrm{RCT}\end{array}$ \\
\hline Calcium channel blockers & $\begin{array}{l}5 \text { studies } \\
1 \mathrm{RCT}\end{array}$ & 0 studies & $\begin{array}{l}2 \text { studies } \\
1 \mathrm{RCT}\end{array}$ & $\begin{array}{l}6 \text { studies } \\
1 \mathrm{RCT}\end{array}$ \\
\hline Magnesium & $\begin{array}{l}3 \text { studies } \\
1 \mathrm{RCT}\end{array}$ & 0 studies & 0 studies & $\begin{array}{l}3 \text { studies } \\
1 \mathrm{RCT}\end{array}$ \\
\hline DC cardioversion & $\begin{array}{l}2 \text { studies } \\
0 \text { RCTs }\end{array}$ & 0 studies & 0 studies & $\begin{array}{l}2 \text { studies } \\
\text { O RCTs }\end{array}$ \\
\hline Anticoagulation* & $\mathrm{N} / \mathrm{A}$ & $\mathrm{N} / \mathrm{A}$ & 0 studies & $\begin{array}{l}2 \text { studies } \\
0 \text { RCTs }\end{array}$ \\
\hline Total & $\begin{array}{l}13 \text { studies } \\
2 \text { RCTs }\end{array}$ & $\begin{array}{l}1 \text { study } \\
0 \text { RCTs }\end{array}$ & $\begin{array}{l}2 \text { studies } \\
1 \mathrm{RCT}\end{array}$ & $\begin{array}{l}16 \text { studies } \\
2 \text { RCTs }\end{array}$ \\
\hline
\end{tabular}

Number of studies in which numerical data for each treatment and outcome could be extracted.

*Outcomes for anticoagulation in both studies were rates of bleeding and ischaemic stroke.

†Other therapies include pilsicainide, digoxin and propafenone.

$\mathrm{DC}$, direct current; RCT, randomised controlled trial.

due to variation in outcome assessment and definition. Of 14 studies assessing rate or rhythm control, 5 stated that electrolyte abnormalities were corrected prior to treatment.

Study outcomes pertaining to rate control were heterogeneous. Due to the inconsistent reporting of rate control efficacy in included studies, we were unable to present these data.

Haemodynamic adverse events (eg, hypotension and bradycardia) associated with amiodarone, calcium channel blockers, beta-blockers or magnesium were assessed in five studies. ${ }^{25-29}$ Rates of stroke and bleeding associated with anticoagulation were reported in two studies. ${ }^{13}{ }^{23}$ No other studies reported adverse events following treatment for NOAF.

\section{Study results}

Figure 2 shows the ORs of treatments compared in each RCT. The efficacy of rhythm control for observational studies is shown in figure 3 .

\section{Amiodarone}

Overall, amiodarone was the most frequently reported treatment. Studies varied in dosing regimen, timing of

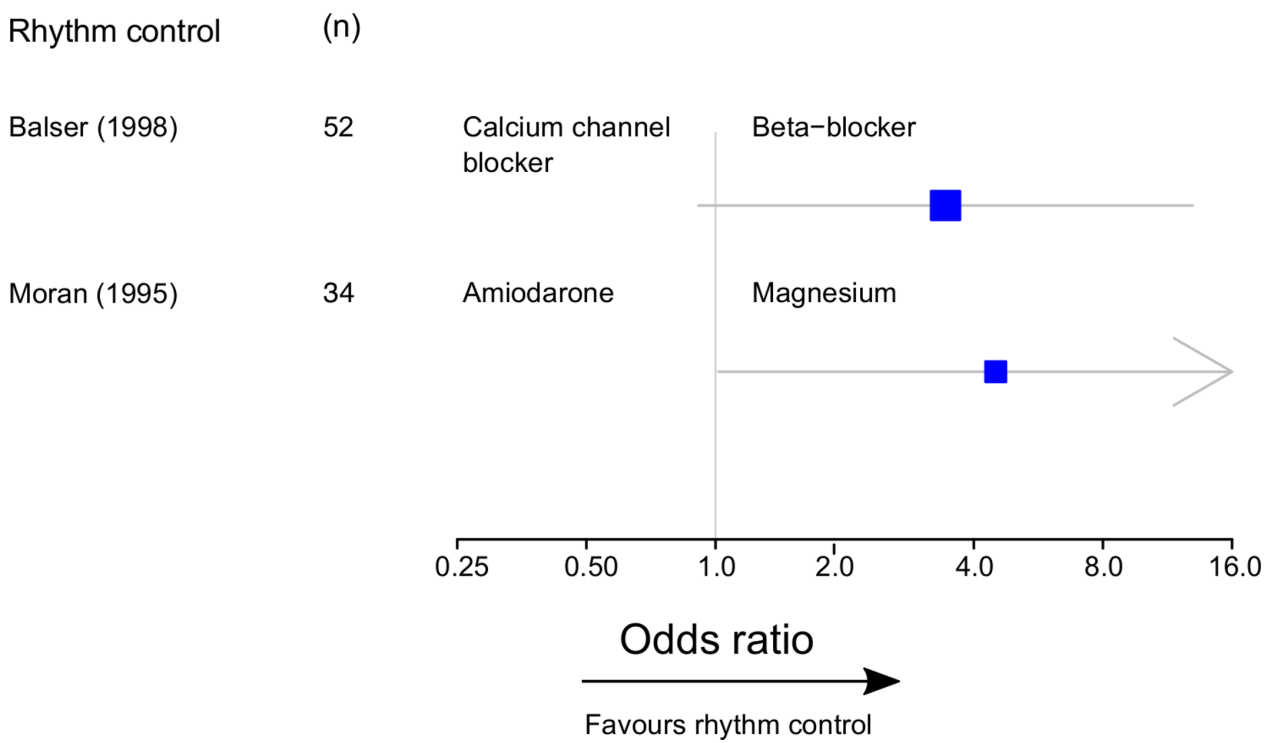

Figure 2 Rate or rhythm control success (RCTs) and ORs comparing agents assessed in RCTs. RCTs, randomised controlled trials. 
Rhythm control

Amiodarone

$\begin{array}{lllr}\text { Amiodarone } & \text { Gerlach (2008) } & \text { Prospective cohort } & 30 \\ & \text { Balik (2017) } & \text { Retrospective cohort } & 15 \\ & \text { Kanji (2012) } & \text { Retrospective cohort } & 103 \\ & \text { Liu (2016) } & \text { Retrospective cohort } & 80 \\ & \text { Mayr (2004) } & \text { Retrospective cohort } & 11 \\ & \text { Mitric (2016) } & \text { Retrospective cohort } & 18 \\ & \text { Yoshida (2018) } & \text { Retrospective cohort } & 10 \\ \text { Beta-blocker } & \text { Balik (2017) } & \text { Retrospective cohort } & 13 \\ & \text { Brown (2018) } & \text { Retrospective cohort } & 22 \\ & \text { Liu (2016) } & \text { Retrospective cohort } & 88 \\ & \text { Okajima (2015) } & \text { Retrospective cohort } & 39 \\ \text { Calcium channel } & \text { Gerlach (2008) } & \text { Prospective cohort } & 31 \\ \text { blocker } & \text { Liu (2016) } & \text { Retrospective cohort } & 66 \\ & \text { Yoshida (2018) } & \text { Retrospective cohort } & 30 \\ & & & \\ & \text { Sleeswijk (2008) } & \text { Prospective cohort } & 29 \\ & \text { Yoshida (2018) } & \text { Retrospective cohort } & 91 \\ & & & \\ \text { DC Cardioversion } & \text { Mayr (2003) } & \text { Prospective cohort } & 37 \\ & \text { Kanji (2012) } & \text { Retrospective cohort } & 26 \\ \text { Digoxin } & \text { Liu (2016) } & \text { Retrospective cohort } & 27 \\ & & & \\ \text { Pilsicainide } & \text { Yoshida (2018) } & \text { Retrospective cohort } & 79 \\ & \text { Balik (2017) } & \text { Retrospective cohort } & 36 \\ & & \end{array}$

(n)

30 03 15 0
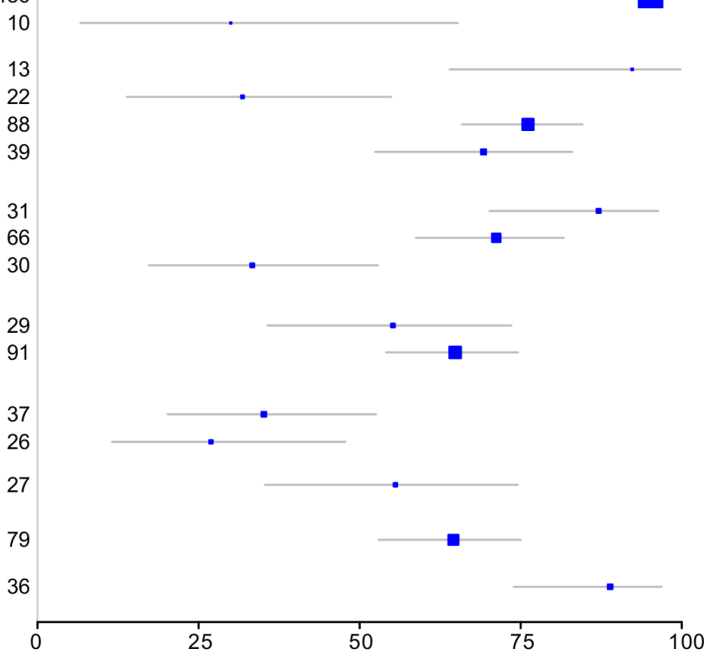

Percentage of patients who reverted to sinus rhythm

Figure 3 Rate or rhythm control success (observational) and efficacy of each agent as reported in observational studies as percentage success. DC, direct current.

outcome assessment and definition of rhythm control. The only RCT of amiodarone reported that it was inferior to magnesium in obtaining rhythm control.

In observational studies, amiodarone success in terms of rhythm control varied from $3 / 10(30.0 \%)^{6}$ to $177 / 186$ $(95.2 \%) .{ }^{29}$ Mitric et al defined successful rhythm control as any reversion to SR during the ICU stay and reported a high success rate for amiodarone $(95.2 \%)$, however AF recurred in $51.4 \% .{ }^{30}$ In the largest studies $(\mathrm{n}>100)$ with an outcome of sustained cardioversion, success occurred in $60.0 \%-73.5 \% .^{52830}$ In three comparative observational studies, amiodarone achieved lower rates of rhythm control than beta-blockers, magnesium and calcium channel blockers. ${ }^{61631}$

Second-line amiodarone use was associated with high rates of success in rate and rhythm control. Amiodarone following initial magnesium therapy resulted in successful rhythm control in 27/29 $(93.1 \%)$ patients in one study. ${ }^{29}$ In another study, amiodarone following initial betablocker or calcium channel blocker therapy achieved rate or rhythm control in $11 / 13(84.6 \%) .^{32}$

Hypotension, defined as mean arterial pressure below $60 \mathrm{~mm} \mathrm{Hg}$, was described in one study and occurred in $6.7 \%$ of 30 patients managed with amiodarone. ${ }^{27}$ Two studies reported no adverse events in response to amiodarone. ${ }^{2528}$ Mayr et al investigated pulmonary toxicity associated with amiodarone use, defined as changes to the $\mathrm{FiO}_{2} / \mathrm{PaO}_{2}$ ratio and found no events in 115 critically ill patients with $\mathrm{NOAF}^{28}$

\section{Beta-blockers}

Three studies investigated short-acting beta-blockers (eg, metoprolol, esmolol and landiolol), ${ }^{242631}$ and five failed to specify the precise agent. ${ }^{56151632}$ In one RCT assessing beta-blocker efficacy, Balser et $a l^{24}$ found 22/26 (85\%) non-cardiac surgical ICU patients with SVA who received esmolol reverted to SR after 12 hours. In observational studies, successful rhythm control using beta-blockers was reported in $7 / 22(31.8 \%)^{31}$ to $12 / 13(92.3 \%)$ patients. $^{30}$ The largest studies reporting the efficacy of beta-blockers described sustained rhythm control in $69.2 \%-84.6 \%$ of participants. ${ }^{162426}$ The only study reporting rate control efficacy for any agent found a $37.9 \%$ heart rate (HR) reduction in 39 patients with sepsis and NOAF managed with landiolol. ${ }^{26}$ Two observational studies directly compared efficacy of beta-blockers with amiodarone and/or calcium channel blockers, finding higher rates of rhythm control with beta-blockers. ${ }^{1631}$

Hypotension requiring discontinuation of a betablocker was identified in $5.9 \%$ of 34 patients in one study. ${ }^{24}$ Okajima et al reported none of the 39 patients treated with a beta-blocker experienced clinically significant bradycardia. ${ }^{26}$

One RCT reported in-hospital mortality in non-cardiac surgical ICU patients, reporting $31 \%$ mortality in patients treated with a beta-blocker $(n=34)$ and $38 \%$ in patients treated with a calcium channel blocker $(n=30) .{ }^{24}$ Walkey et al reported in-hospital mortality, comparing betablockers with amiodarone, calcium channel blockers and digoxin in 7478 propensity-matched septic patients with NOAF. ${ }^{15}$ Patients given beta-blockers had lower mortality rates than those given amiodarone (RR 0.67, 95\% CI 0.59 to 0.77 ) or digoxin ( $\mathrm{RR} 0.75,95 \%$ CI 0.64 to 0.88 ). Mortality rates with beta-blockers were similar to calcium channel blockers (RR 0.99, 95\% CI 0.86 to 1.15 ). 


\section{Calcium channel blockers}

One RCT investigated calcium channel blockers for efficacy of rhythm control, reporting success in 16/26 $(61.5 \%)$ patients at 12 hours. ${ }^{24}$ Observational studies reported successful cardioversion using calcium channel blockers in $10 / 30(30 \%)^{6}$ to $27 / 31(87.1 \%)$ patients. ${ }^{27}$ Calcium channel blockers were compared with other agents in three studies. ${ }^{6} 1627$ One observational study comparing beta-blockers with calcium channel blockers found greater efficacy in rhythm control with the former. ${ }^{16}$ Two studies found calcium channel blockers to be similarly efficacious to amiodarone, ${ }^{627}$ and one study found calcium channel blockers to be more effective than amiodarone, though this study was of lower quality. ${ }^{16}$ Hypotension occurred in $1 / 31(3.2 \%)$ and $1 / 30(3.3 \%)$ of patients receiving a calcium channel blocker. ${ }^{24} 27$

\section{Magnesium}

The only RCT of magnesium reported superior efficacy to amiodarone, with rhythm control achieved in 14/18 $(77.8 \%)$ patients treated for 24 hours to a target serum concentration of $1.5-2.0 \mathrm{mmol} / \mathrm{L}^{25}$. Across all studies, successful rhythm control with magnesium occurred in $55.2 \%{ }^{32}$ to $77.8 \%{ }^{25}$ of patients. A retrospective study of patients receiving magnesium found that 59/91 (64.8\%) reverted to $\mathrm{SR},{ }^{6}$ though the therapeutic target for magnesium level was not reported. A prospective observational study titrated magnesium to a serum concentration of $2.0-3.0 \mathrm{mmol} / \mathrm{L}$ and reported rhythm control in 16/29 $(55 \%)$ patients after 1 hour. ${ }^{32}$ Magnesium was directly compared with amiodarone and a calcium channel blocker in one observational study which found the highest success in rhythm control rate with magnesium. ${ }^{6}$ No adverse events were identified with magnesium use in any study.

\section{Electrical therapy}

DCC was investigated in only two observational studies, reporting efficacy of $26.9 \%$ and $35.1 \% .^{5}{ }^{14}$ Mayr et al reported primary success in $13 / 37(35.1 \%)$ critically ill patients with NOAF at 1 hour. ${ }^{14}$ By 24 hours, only 6 $(13.5 \%)$ of these 37 patients remained in SR. Another study assessed the efficacy of DCC, reporting success (defined as maintained SR for 24 hours) in 7/26 (26.9\%) patients; 18 of these received amiodarone prior to or during DCG. ${ }^{5}$

\section{Other therapies}

Successful rhythm control using other treatments ranged from $55.6 \%^{16}$ to $89.0 \%{ }^{30}$ Digoxin use was reported in one efficacy study; rhythm control was achieved in 15/27 $(55.6 \%)$ patients. ${ }^{16}$ Single observational studies investigated the efficacy of pilsicainide and propafenone in rhythm control for this patient population, with success rates of $51 / 79(64.6 \%)$ and $32 / 36(89 \%)$ respectively. ${ }^{630}$

\section{Anticoagulation}

We found two observational studies of anticoagulation in critically ill patients with NOAF. A retrospective analysis of 5585 patients with sepsis and NOAF found that $37.6 \%$ were given anticoagulants during admission. ${ }^{13}$ Anticoagulant use did not significantly affect the risk of in-hospital stroke (RR $0.85,95 \%$ CI 0.57 to 1.27 ) or risk of bleeding (RR $0.97,95 \%$ CI 0.83 to 1.14 ). Another retrospective analysis of 102 critically ill patients with sepsis and NOAF reported rates of ischaemic stroke and bleeding after 3 years follow-up. In patients who were prescribed anticoagulation at discharge, rates of ischaemic stroke were $2 / 28(7.1 \%)$ compared with $4 / 73(5.5 \%)$ in those who were not prescribed anticoagulants. ${ }^{23}$ Rates of bleeding were $5 / 25(20.0 \%)$ in the anticoagulated group compared with $15 / 76(19.7 \%)$ in the control.

\section{DISCUSSION}

Our review provides an up-to-date assessment of the evidence for the efficacy of treatments used for managing NOAF in critically ill patients. Our results show that amiodarone, beta-blockers, calcium channel blockers and magnesium achieved similar rates of rhythm control across studies. We therefore recommend further trials focus on comparing these four treatments. Digoxin and DCC achieved lower rates of successful rhythm control in published studies. Our review did not find evidence to support the use of anticoagulation for managing this patient group.

We extracted data from 16 studies reporting treatment outcomes. This includes nine studies published after the search performed by Yoshida et al. in 2015 who by comparison identified four studies providing efficacy data of individual treatments. ${ }^{2}$ The 2008 review by Kanji et $a l^{12}$ reported on four RCTs, two of which we excluded on the basis of a failure to describe exclusion of participants with pre-existing AF. Our review represents a far broader evidence base than previous systematic reviews. A recent scoping review of all aspects of NOAF in critically ill patients has been undertaken, and due to its broad scope it did not report management strategies within ICU in detail. ${ }^{1}$ By focusing solely on management of NOAF in patients admitted to a medical, surgical or general ICU, we present a detailed and modern assessment of the reported effects of different agents in these patients.

\section{Rhythm control}

Amiodarone, beta-blockers, calcium channel blockers and magnesium achieved similar rates of sustained rhythm control in critically ill patients with NOAF. Although beta-blockers and calcium channel blockers are considered rate control agents, they appear to be effective in achieving rhythm control. In comparative studies, beta-blockers and magnesium tended to be slightly more successful in achieving rhythm control than calcium channel blockers and amiodarone. Magnesium may have an important role as a first-line treatment, reducing the need for higher risk interventions. While first-line magnesium was successful in only $55 \%$ of patients in one study, this may be an underestimate due to the 1-hour end point 
used. ${ }^{29}$ This study also suggested that the majority of patients who did not convert to SR with magnesium alone did so with the use of second-line amiodarone. Similarly, Brown et al reported excellent efficacy in achieving rate and rhythm control with second-line amiodarone following treatment with a beta-blocker. ${ }^{32}$ Amiodarone may therefore have an important role as a second-line therapy in patients with NOAF.

Two RCTs compared the efficacy of treatments in regard to rhythm control (figure 2). One of these RCTs, comparing magnesium to amiodarone, reported superior efficacy using magnesium. ${ }^{25}$ An RCT comparing betablockers to calcium channel blockers was underpowered to detect a difference in rhythm control efficacy, despite a tendency towards the beta-blocker. ${ }^{24}$ In four observational comparative studies, beta-blockers and magnesium tended to be more effective than calcium channel blockers and amiodarone. ${ }^{6} 162731$ Further research is needed to compare rhythm control agents in efficacy and safety. In line with Walkey et $a l^{33}$ we conclude that digoxin and DCC may be less effective than other therapies in critically ill patients with NOAF.

Although five studies reported correction of electrolyte abnormalities prior to treatment, methods and targets of correction were not described. Electrolytes corrected were potassium and magnesium, though some studies failed to specify an electrolyte.

\section{Rate control}

In patients with $\mathrm{AF}$, rate control is an equally important outcome as rhythm control. ${ }^{34}$ It is possible that for critically ill NOAF patients treated with beta-blockers or calcium channel blockers, rate control leads to rhythm control by allowing for spontaneous cardioversion. ${ }^{27}$ Despite this, studies of treatment efficacy report rate control data inconsistently. Balser et al reported a mean ventricular rate following drug therapy but failed to report the pretreatment rates or the proportion of people in whom rate control occurred. ${ }^{24}$ Two included studies report rate and rhythm control as a combined outcome, ${ }^{29} 32$ while another three studies report outcomes for rate control without separating results for the treatments given. ${ }^{5} 2528$ Two studies provide the mean HR prior to and after treatment but fail to report the proportion of patients in whom treatment was successful. ${ }^{26} 27$ Due to the heterogeneous reporting of rate control data, we were unable to provide detailed results of treatment efficacy in bringing about rate control. It is therefore essential for future studies to report rate control data in a standardised manner to enable robust comparison of treatment efficacy for critically ill patients with NOAF.

\section{Adverse events}

Adverse events associated with treatments were infrequently reported, providing insufficient data to compare event rates for most therapies. Two studies (49 participants) investigated adverse events associated with magnesium use, finding none. Magnesium appeared to carry low risk of adverse outcomes, but larger studies are needed to assess this. Studies reporting adverse events tended to have small cohorts that may not detect uncommon events.

\section{Mortality}

Only one retrospective study was sufficiently powered to consider mortality differences between treatments. Walkey et al reported a reduction in mortality associated with the use of beta-blockers when compared with amiodarone and digoxin in propensity-matched patients with sepsis and NOAF. ${ }^{15}$ Patients were matched by year of hospitalisation, demographics, comorbidities, acute organ failure, organ-supportive therapy, source of sepsis and hospital characteristics. This finding needs to be interpreted with caution, as septic patients were defined using International Classification of Diseases codes and thus may not reflect the general critically ill patient.

\section{Anticoagulation}

This review highlights the lack of evidence underlying the use or avoidance of therapeutic dose anticoagulants in critically ill patients with NOAF. The only study of sufficient size to investigate the effects of anticoagulation was of patients with sepsis and was not restricted to patients being managed in ICU. ${ }^{13}$ This study reported rates of stroke occurring during hospital admission for patients treated with therapeutic doses of intravenous or subcutaneous anticoagulant medications. The rate of this uncommon event was not significantly affected by anticoagulant use during admission. The second study of anticoagulant use reported rates of stroke and bleeding over 3 years in patients prescribed anticoagulants on discharge from hospital; this was underpowered to report a difference in complications. ${ }^{23}$ Neither study of anticoagulation provided details regarding the duration of treatment.

\section{Limitations of this review}

The findings of our review were limited by a lack of recent RCTs comparing therapies in critically ill patients. The majority of studies were observational in design, with small patient cohorts. Studies varied considerably in their patient populations, outcomes and interventions. This variability meant that we were unable to pool data for treatment efficacy. Both RCTs in this review are over 20 years old, and no longer reflect current practices in critical care. RCTs were also small, with no common treatment comparisons, rendering a meta-analysis impossible. We were unable to account for rates of spontaneous cardioversion that occurred in studies which serves as a confounder to our reported rates of successful rhythm control.

\section{Research recommendations}

There remains a need for further research to compare treatments for NOAF in critically ill patients. We suggest that large cohort studies are conducted using standardised outcomes to identify the key treatments of interest and to guide the design of subsequent RCTs. Definitions of NOAF used in future studies need to be 
agreed. Amiodarone, beta-blockers, calcium channel blockers and magnesium should be compared for efficacy in studies of sufficient size to be able to detect clinically meaningful differences between individual treatments. Combined therapies with first-line magnesium may also merit further study.

The most common definition of rhythm control success in our review was SR maintained for 24 hours. This may make it an appropriate definition for future studies. The reporting of rate control efficacy should be brought into line with current guidance. A review of trial data comparing outcomes for rate control in chronic $\mathrm{AF}$ found that a target resting rate $<110$ was a valid outcome for detecting symptoms and complications from disease. ${ }^{35}$ These findings were not specific to a critically ill patient population. To our knowledge, there are no recommendations for the use of percentage change in HR or change in mean HR as an outcome for rate control in $\mathrm{AF}$. We recommend that future studies adopt a target HR of $<110 \mathrm{bpm}$ and report the proportion of patients in whom this target was successfully reached at a time point of 24 hours. This would bring the reporting of rate control data into line with existing studies reporting the efficacy in terms of rhythm control. Secondary outcomes reported should include mortality, duration of ICU and hospital admission and adverse events. The lack of adequate reporting or investigation of adverse events is concerning. Future studies should include hypotension or bradycardia requiring treatment modification and complications associated with amiodarone use (eg, pulmonary or hepatic toxicity).

\section{CONCLUSION}

Our review has shown similar efficacy of beta-blockers, amiodarone, calcium channel blockers and magnesium in achieving rhythm control, but with limited evidence. First-line magnesium with amiodarone for nonresponders achieved high rates of rhythm control in one small study. Electrical cardioversion and digoxin may be less effective in critically ill patients with NOAF. There is insufficient data to inform the use of anticoagulation, and this is a deficit that needs to be rectified. We suggest standardised outcomes for future studies to guide practice in managing this important condition.

Twitter Liam Joseph 0'Bryan @Liam0Bryan2 and Jonathan Bedford @JonBedford

Acknowledgements We thank Julie Darbyshire, Nuffield Department of Clinical Neurosciences, University of Oxford, Oxford and Rachael Fox, University of Melbourne, Melbourne, Australia for their assistance in manuscript preparation.

Contributors All authors made substantial contributions towards the review and drafting the manuscript. DY and PJW conceived and designed the review. TP, JB, OCR and LJO designed the search. LJO and JB reviewed articles. LJO and OCR conducted the search, extracted data and performed quality assessment. OCR produced the figures. All authors contributed to the synthesis of, read and reviewed the final manuscript.

Funding Peter Watkinson is supported by the NIHR Biomedical Research Centre, Oxford.

Competing interests None declared.
Patient consent for publication Not required.

Provenance and peer review Not commissioned; externally peer reviewed.

Data availability statement Data sharing not applicable as no data sets generated and/or analysed for this study.

Open access This is an open access article distributed in accordance with the Creative Commons Attribution Non Commercial (CC BY-NC 4.0) license, which permits others to distribute, remix, adapt, build upon this work non-commercially, and license their derivative works on different terms, provided the original work is properly cited, appropriate credit is given, any changes made indicated, and the use is non-commercial. See: http://creativecommons.org/licenses/by-nc/4.0/.

\section{ORCID iDs}

Liam Joseph 0'Bryan http://orcid.org/0000-0002-5565-914X

Jonathan Bedford http://orcid.org/0000-0001-9455-022X

Peter J Watkinson http://orcid.org/0000-0003-1023-3927

\section{REFERENCES}

1 Wetterslev M, Haase N, Hassager C, et al. New-onset atrial fibrillation in adult critically ill patients: a scoping review. Intensive Care Med 2019;45:928-38.

2 Yoshida T, Fujii T, Uchino S, et al. Epidemiology, prevention, and treatment of new-onset atrial fibrillation in critically ill: a systematic review. J Intensive Care 2015;3:19.

3 Meierhenrich R, Steinhilber E, Eggermann C, et al. Incidence and prognostic impact of new-onset atrial fibrillation in patients with septic shock: a prospective observational study. Crit Care 2010;14:R108.

4 Klein Klouwenberg PMC, Frencken JF, Kuipers S, et al. Incidence, predictors, and outcomes of new-onset atrial fibrillation in critically ill patients with sepsis. A cohort study. Am J Respir Crit Care Med 2017;195:205-11.

5 Kanji S, Williamson DR, Yaghchi BM, et al. Epidemiology and management of atrial fibrillation in medical and noncardiac surgical adult intensive care unit patients. J Crit Care 2012;27:326.e1-8.

6 Yoshida T, Uchino S, Yokota T, et al. The impact of sustained newonset atrial fibrillation on mortality and stroke incidence in critically ill patients: a retrospective cohort study. J Crit Care 2018;44:267-72.

7 Chen AY, Sokol SS, Kress JP, et al. New-onset atrial fibrillation is an independent predictor of mortality in medical intensive care unit patients. Ann Pharmacother 2015;49:523-7.

8 Christian S-A, Schorr C, Ferchau L, et al. Clinical characteristics and outcomes of septic patients with new-onset atrial fibrillation. J Crit Care 2008;23:532-6.

9 January CT, Wann LS, Alpert JS, et al. 2014 AHA/ACC/HRS guideline for the management of patients with atrial fibrillation: Executive summary. Circulation 2014;130:2071-104.

10 Kirchhof P, Benussi S, Zamorano JL, et al. 2016 ESC guidelines for the management of atrial fibrillation developed in collaboration with EACTS. Russ J Cardiol 2017;147:7-86.

11 National Institute for Health and Care Excellence. Atrial fibrillation: the management of atrial fibrillation. In: NICE clinical guideline 180. 180th edn. London: NICE Clinical Guidelines, 2014.

12 Kanji S, Stewart R, Fergusson DA, et al. Treatment of new-onset atrial fibrillation in noncardiac intensive care unit patients: a systematic review of randomized controlled trials. Crit Care Med 2008;36:1620-4

13 Walkey AJ, Quinn EK, Winter MR, et al. Practice patterns and outcomes associated with use of anticoagulation among patients with atrial fibrillation during sepsis. JAMA Cardiol 2016;1:682-90.

14 Mayr A, Ritsch N, Knotzer H, et al. Effectiveness of direct-current cardioversion for treatment of supraventricular tachyarrhythmias, in particular atrial fibrillation, in surgical intensive care patients. Crit Care Med 2003;31:401-5.

15 Walkey AJ, Evans SR, Winter MR, et al. Practice patterns and outcomes of treatments for atrial fibrillation during sepsis: a propensity-matched cohort study. Chest 2016;149:74-83.

16 Liu WC, Lin WY, Lin CS, et al. Prognostic impact of restored sinus rhythm in patients with sepsis and new-onset atrial fibrillation. Crit Care 2016;20:373.

17 Liberati A, Altman DG, Tetzlaff J, et al. The PRISMA statement for reporting systematic reviews and meta-analyses of studies that evaluate healthcare interventions: explanation and elaboration. BMJ 2009;339:b2700.

18 Ouzzani M, Hammady $\mathrm{H}$, Fedorowicz Z, et al. Rayyan-a web and mobile app for systematic reviews. Syst Rev 2016;5:210. 
19 Elmagarmid A, Fedorowicz Z, Hammady H, et al. Rayyan: a systematic reviews web app for exploring and filtering searches for eligible studies for Cochrane Reviews. In: Evidence-Informed public health: opportunities and challenges Abstracts of the 22nd Cochrane Colloquium. John Wiley \& Sons, 2014: 9.

20 Wells GA, Shea B, O'Connell D, et al. The Newcastle-Ottawa Scale (NOS) for assessing the quality of nonrandomised studies in metaanalyses. The Ottawa Hospital Research Institute, 2010.

21 Bedford J, Harford M, Petrinic T, et al. Risk factors for new-onset atrial fibrillation on the general adult ICU: protocol for a systematic review. BMJ Open 2018;8:e024640.

22 Higgins JPT, Altman DG, Gøtzsche PC, et al. The Cochrane Collaboration's tool for assessing risk of bias in randomised trials. BMJ 2011;343:d5928.

23 Quon MJ, Behlouli H, Pilote L. Anticoagulant use and risk of ischemic stroke and bleeding in patients with secondary atrial fibrillation associated with acute coronary syndromes, acute pulmonary disease, or sepsis. JACC Clin Electrophysiol 2018;4:386-93.

24 Balser JR, Martinez EA, Winters BD, et al. B-Adrenergic blockade accelerates conversion of postoperative supraventricular tachyarrhythmias. Anesthesiology 1998;89:1052-9.

25 Moran JL, Gallagher J, Peake SL, et al. Parenteral magnesium sulfate versus amiodarone in the therapy of atrial tachyarrhythmias: a prospective, randomized study. Crit Care Med 1995;23:1816-24.

26 Okajima M, Takamura M, Taniguchi T. Landiolol, an ultra-short-acting $\beta 1$-blocker, is useful for managing supraventricular tachyarrhythmias in sepsis. World J Crit Care Med 2015;4:251-7.
27 Gerlach AT, Kane-Gill SL, Dasta JF, et al. Diltiazem versus amiodarone for new-onset atrial arrhythmias in non-cardiac post surgical patients: a cohort study. Crit Care Shock 2008;11:94-106.

28 Mayr AJ, Dünser MW, Ritsch N, et al. High-dosage continuous amiodarone therapy to treat new-onset supraventricular tachyarrhythmias in surgical intensive care patients: an observational study. Wien Klin Wochenschr 2004:116:310-7.

29 Sleeswijk ME, Tulleken JE, Van Noord T, et al. Efficacy of magnesium-amiodarone step-up scheme in critically ill patients with new-onset atrial fibrillation: a prospective observational study. $J$ Intensive Care Med 2008;23:61-6.

30 Mitrić G, Udy A, Bandeshe $\mathrm{H}$, et al. Variable use of amiodarone is associated with a greater risk of recurrence of atrial fibrillation in the critically ill. Crit Care 2016;20:90.

31 Balik M, Kolnikova I, Maly M, et al. Propafenone for supraventricular arrhythmias in septic shock-Comparison to amiodarone and metoprolol. J Crit Care 2017;41:16-23.

32 Brown M, Nassoiy S, Chaney W, et al. Impact and treatment success of new-onset atrial fibrillation with rapid ventricular rate development in the surgical intensive care unit. J Surg Res 2018;229:66-75.

33 Walkey AJ, Hogarth DK, Lip GYH. Optimizing atrial fibrillation management: from ICU and beyond. Chest 2015;148:859-64.

34 Wyse DG, Waldo AL, DiMarco JP, et al. A comparison of rate control and rhythm control in patients with atrial fibrillation. N Engl $J$ Med 2002;347:1825-33.

35 Van Gelder IC, Rienstra M, Crijns HJGM, et al. Rate control in atrial fibrillation. Lancet 2016;388:818-28. 